\title{
Pesquisa de percepção sobre ensino de ciências: mudanças climáticas e desmatamento estão entre os temas mais relevantes para estudantes secundaristas
}

Science teaching perception survey: climate change and deforestation are among the most relevant topics for high school students

Rodrigo Bastos Cunha ${ }^{1}$

\section{Resumo}

Nas últimas décadas, ganharam força, no Brasil, as pesquisas sobre ensino de ciências com propostas de abordagem das relações entre ciência, tecnologia e sociedade, conhecida como ensino CTS. Nessa perspectiva, as aulas de biologia, física e química do ensino médio deveriam abordar os impactos positivos e negativos da ciência para a sociedade e o ambiente. Este artigo apresenta os resultados de uma pesquisa de percepção sobre ensino de biologia, física e química com estudantes secundaristas de todo o país. O objetivo da pesquisa é ver o quanto o ensino CTS está consolidado nas salas de aula do ensino médio e seu impacto na percepção dos estudantes. Utilizou-se, como ferramenta, um questionário pela internet com perguntas fechadas, em que o respondente não se identifica. Os resultados apontam que temas como mudanças climáticas e desmatamento têm relevância mais alta para os estudantes do que temas do cânone da ciência.

Palavras chave: ensino de biologia; ensino de física; ensino de química.

\section{Abstract}

In the last decades, research on science teaching has gained strength in Brazil with proposals to approach the relations between science, technology and society, known as STS teaching. From this perspective, high school biology, physics and chemistry classes should address the positive and negative impacts of science on society and the environment. This article presents the results of a perception survey on the teaching of biology, physics and chemistry with high school students from all over the country. The aim of the research is to see how much STS teaching is consolidated in high school classrooms and its impacts on the perceptions of students. As a tool, a questionnaire with closed questions was used, in which the respondent does not identify himself. The results show that themes such as climate change and deforestation are of higher relevance to students than themes in the science canon.

Keywords: biology teaching; physics teaching; chemistry teaching. 


\section{Introdução}

No final de junho de 2021, a Agência Nacional de Energia Elétrica (Aneel) decidiu aumentar o valor cobrado na tarifa da conta de luz em mais de 50\%, em decorrência da falta de chuvas. Com o nível mais baixo dos reservatórios que alimentam as usinas hidrelétricas, o Brasil precisa acionar usinas mais caras e poluentes, as termoelétricas, que geram energia a partir da queima de combustíveis fósseis. Temas atuais como esse poderiam aparecer em aulas de biologia, física e química, no ensino médio, tanto na abordagem de conhecimentos científicos, como combustão e termodinâmica, quanto de questões sociais, como o custo da energia no orçamento das famílias de baixa renda; econômicas, como o impacto da falta de chuvas e do custo da energia para o setor produtivo; e ambientais, como as causas da estiagem prolongada e os riscos do aumento da queima de combustíveis fósseis.

Esse é um exemplo do que autores como Strieder e Kawamura (2008) chamam de temas geradores, que possibilitam não apenas a contextualização do conhecimento científico a ser ensinado na escola, mas, principalmente, a realização de debates com os alunos e seu engajamento para transformar a realidade a seu redor e participar em decisões envolvendo ciência e tecnologia. Trata-se de um tipo de abordagem sobre as relações entre ciência, tecnologia e sociedade, que ficou conhecida como ensino CTS e ganhou força, no Brasil, nas últimas décadas (ver, por exemplo, SANTOS; SCHNELTZER, 1997; SANTOS; MORTIMER, 2001; SANTOS, 2007; MASCIO, 2009; FERREIRA; 2011; ZANI et al, 2013; SANTANA; BASTOS; TEIXEIRA, 2015; CAMPOS, 2017). Após tantos anos de contribuições das pesquisas sobre ensino CTS, qual a percepção dos estudantes do ensino médio de hoje sobre as relações entre ciência, tecnologia e sociedade?

Este artigo tem como objetivo apresentar os resultados de uma pesquisa de percepção sobre ensino de biologia, física e química com estudantes do ensino médio de todo o país, de escolas públicas de ensino regular, escolas públicas de ensino técnico e de escolas particulares. Os estudantes opinaram sobre qual deve ser o foco do ensino dessas disciplinas, o que deve ser privilegiado; responderam a questões envolvendo relações CTS, como, por exemplo, os benefícios e os riscos dos avanços científicos e tecnológicos; e usaram uma escala de avaliação para dizer a relevância que atribuem a temas socioambientais, semelhantes ao apresentado no início deste artigo, e a temas do cânone da ciência, já tradicionais no ensino de biologia, física e química.

\section{Metodologia}

As pesquisas de percepção sobre ciência e tecnologia realizadas no Brasil (FAPESP, 2005; MCTI, 2006; MCTI, 2010; FAPESP, 2011; CGEE, 2017; CGEE, 2019), com levantamentos em larga escala, têm sido adaptadas em estudos acadêmicos com foco no público escolar, tanto de professores (MORALES; COELHO, 2015) quanto de estudantes (BONETT et al, 2008; COELHO; MORALES; VOGT, 2016). Esse tipo de pesquisa aborda, entre outras coisas, o nível de interesse por ciência e tecnologia em comparação com outros temas, o nível de acesso a informações sobre ciência e tecnologia e o grau de confiança no cientista em comparação com outras áreas de atuação.

Para esta pesquisa de percepção sobre ensino de ciências apresentada aqui, foi criado um questionário voltado para estudantes do ensino médio, com questões opinativas 
específicas sobre o foco do ensino e sobre relações entre ciência, tecnologia e sociedade, além de uma lista de temas socioambientais e de temas do cânone da ciência, para o respondente atribuir o grau de relevância. O questionário foi criado através do Google Docs, ficou disponível para respostas entre janeiro e abril de 2021 e os respondentes não se identificavam.

A estrutura do questionário se divide em quatro tipos de questões: três sobre o perfil do entrevistado (gênero, tipo de escola em que estuda e tipo de curso que pretende fazer na universidade); duas sobre foco do ensino (a ciência em si, questões sociais ligadas à ciência ou ambas as coisas) e o que o ensino deve privilegiar (a formação de cientistas, a formação para tomada de decisões como cidadão ou ambas as coisas); três perguntas usando a Escala de Likert, para avaliar o quanto os entrevistados concordam ou não com determinadas afirmações envolvendo relação entre ciência, tecnologia e sociedade; e uma lista com doze temas (cinco socioambientais e sete do cânone da ciência), em ordem aleatória, para que fosse atribuída relevância em uma escala de zero (0) a dez (10), em que zero é nada relevante e dez é extremamente relevante.

Para atingir o público alvo da pesquisa, foram enviados emails para coordenações pedagógicas de escolas de ensino médio de todo o país, tanto públicas de ensino regular quanto públicas de ensino técnico e particulares. Esses emails foram obtidos através das secretarias de educação de cada unidade da federação. Professores de biologia, física e química que participaram de eventos acadêmicos sobre ensino de ciências, cujos emails estavam disponíveis nos anais, também colaboraram para a divulgação da pesquisa junto a estudantes. Outra colaboração importante para se obter uma participação significativa de estudantes foi dada pelos programas de pós-graduação em ensino de ciências que trabalham com formação de professores, os quais repassaram, em suas escolas, os convites para seus estudantes participarem da pesquisa.

\section{Resultados}

O total de respostas coletadas em quatro meses foi 1122. A maioria dos estudantes que responderam (61,9\%) são meninas, 37,3\% são meninos e 0,8\% se identificam com outros gêneros, como não binário. A maioria dos respondentes (51,8\%) estuda em escola pública de ensino regular, 25,9\% estuda em escola pública de ensino técnico e 22,3\% estuda em escola particular. É bastante alto (40,9\%) o percentual dos que ainda não decidiram que tipo de curso pretende fazer na universidade; $21,4 \%$ pretende fazer algum curso de ciências humanas; $19,1 \%$ pretende fazer algum curso de ciências biológicas; 15,6\% pretende fazer algum curso de ciências exatas; e 3\% não pretende fazer universidade.

A primeira pergunta opinativa questionava qual deveria ser o foco do ensino de biologia física e química. O maior percentual de respostas $(44,5 \%)$ é dos que consideram que o foco do ensino deve ser tanto a ciência em si quanto questões sociais ligadas à ciência; para 21,4\% dos estudantes, o foco deve ser a ciência em si, o método científico e suas aplicações; para 18,2\%, o foco do ensino deve ser questões sociais da vida dos estudantes com alguma relação com ciência e tecnologia; $7,7 \%$ dos estudantes considera que o foco do ensino deve ser maior na ciência em si do que em questões sociais; $6,8 \%$ não souberam opinar; e apenas 1,5\% considera que o foco do ensino deve maior em questões sociais do que na ciência em si. 
Embora não seja a opinião da maioria dos estudantes, predomina o equilíbrio entre a ciência em si e questões sociais ligadas à ciência como foco do ensino, o que já pode ser considerado como consequência de uma inserção cada vez maior de propostas de temas geradores nas escolas, como as sugeridas por Strieder e Kawamura (2008). Porém, independentemente de questões sociais serem usadas como ponto de partida para a abordagem de conhecimentos científicos canônicos, para uma grande parcela dos estudantes, ambas as coisas devem fazer parte do foco do ensino.

A segunda pergunta opinativa era sobre o que o ensino de biologia, física e química deve privilegiar. A maioria $(60,2 \%)$ considera que o ensino deve privilegiar tanto a formação de novos cientistas quanto a formação dos estudantes para tomada de decisões como consumidor e cidadão; para 11,6\%, o ensino deve privilegiar mais a formação para tomada de decisões do que a formação de cientistas; $9,6 \%$ consideram que o ensino deve privilegiar a formação para tomada de decisões; para 7,6\%, o ensino deve privilegiar mais a formação de cientistas do que a formação para tomada de decisões; 6,3\% não souberam opinar; e $4,6 \%$ consideram que o ensino deve privilegiar a formação de novos cientistas.

Esses dados revelam outra provável consequência das abordagens CTS no ensino de biologia, química e física: a alta demanda dos estudantes por um ensino que privilegie a formação para tomada de decisões em patamar de igualdade com a formação de novos cientistas. Isso se relaciona com o que Aikenhead (1994) e Roberts (2007) observam a respeito de dois diferentes grupos de estudantes que devem ser considerados pelo ensino de ciências: a minoria representada pelos que vão seguir carreira científica e a maioria, ou seja, todos os demais. Vale lembrar que 51,8\% dos estudantes que responderam ao questionário são de escolas públicas de ensino regular, cuja realidade social acaba levando muitos a priorizar mais a busca imediata por um emprego do que o longo caminho para uma carreira científica, que se inicia em cursos de pós-graduação.

A primeira pergunta envolvendo relação entre ciência, tecnologia e sociedade buscava avaliar o grau de concordância com a seguinte afirmação: "As intervenções humanas na natureza através da ciência ou da tecnologia não são sempre benéficas e também não são sempre maléficas". O grau de concordância é bastante alto: a maioria dos estudantes $(50,8 \%)$ concorda totalmente; 33,4\% concorda parcialmente; $11,7 \%$ não concorda nem discorda; 3,1\% discorda parcialmente; e apenas 1\% discorda totalmente.

Para Ayala (1996), ser uma pessoa cientificamente letrada implica que o apoio ou não a um programa de governo, como a construção de uma usina nuclear, não deve ser baseado na crença de que a manipulação de recursos naturais é sempre prejudicial e tampouco de que é sempre benéfica. Uma possibilidade de investigação em futuro estudo qualitativo com grupo focal de estudantes seria verificar as restrições alegadas entre os que concordam apenas parcialmente com aquela afirmação.

Outra pergunta buscou avaliar o grau de concordância com a seguinte afirmação sobre relações CTS: "As soluções da ciência ou da tecnologia para resolver um determinado problema podem, eventualmente, gerar outro tipo de problema". Embora esta afirmação tenha certa relação semântica com a anterior, aqui o grau de concordância dos estudantes é menor: $43,7 \%$ concorda parcialmente; $29,6 \%$ concorda totalmente; $18,5 \%$ não concorda nem discorda; 6,3\% discorda parcialmente; e 1,9\% discorda totalmente.

Um estudo qualitativo futuro poderia investigar as diferenças de atitudes responsivas a afirmações mais assertivas, envolvendo o advérbio "sempre", e afirmações que expressam uma possibilidade, envolvendo o advérbio "eventualmente". Independentemente disso, a 
concordância não tão alta ou com restrições, no segundo caso, pode levar a reflexões sobre abordagem CTS no ensino.

Um tema que poderia ilustrar um debate com os alunos envolvendo essa questão seria a construção de usina hidrelétrica em região mais plana, com pouca queda d'água. Nesse caso, a solução para o problema de geração de energia, ainda que seja uma alternativa com fonte renovável e não poluente, requer o alagamento de uma vasta região para construção de reservatório, o que pode gerar problemas ambientais e sociais, quando envolve o deslocamento de famílias do local.

A pergunta seguinte, além de se relacionar com as anteriores, envolve um item bastante presente nas propostas de ensino CTS, o debate. Buscou-se avaliar o grau de concordância com a seguinte afirmação: "Para participar de um debate sobre questões envolvendo ciência e tecnologia, é preciso considerar os possíveis riscos e benefícios dos avanços científicos e tecnológicos". Das três perguntas envolvendo relações CTS, esta foi a que obteve o maior percentual de concordância total dos estudantes, 59\%; 24,9\% concordam parcialmente; 12,7\% não concordam nem discordam; 2,5\% discordam parcialmente; e 0,9\% discordam totalmente. Entre os objetivos do ensino CTS, aponta-se a capacitação para participar de debates que questionem os modelos de desenvolvimento científico e tecnológico e considerem benefícios e riscos da ciência e da tecnologia (SANTOS; SCHNELTZER, 1997; SANTOS; MORTIMER, 2001; SANTOS, 2007).

O questionário da pesquisa apresentava aos estudantes, em sua parte final, uma lista com doze temas, dos quais cinco são socioambientais e sete são do cânone da ciência, solicitando que eles atribuíssem a relevância de cada tema em uma escala de zero a dez, em que zero é nada relevante e dez é extremamente relevante. Quatro dos cinco temas socioambientais aparecem no topo da lista como os mais relevantes para os estudantes: a relevância média para "Efeito estufa, aquecimento global e mudanças climáticas" foi de 8,93; para "Biodiversidade, desmatamento e preservação ambiental", foi de 8,91; para "Vantagens e desvantagens das diversas fontes de geração de energia", foi de 8,28; e para "Benefícios e riscos da energia nuclear e acidentes ao longo da história", foi de 8,13. Dos temas socioambientais da lista, apenas "Bomba atômica e armas de destruição em massa" teve relevância média abaixo de 8: ficou em 7,40.

Os dois temas do cânone da ciência mais relevantes para os estudantes são "As Leis de Newton", com relevância média de 7,57, e "A Teoria da Evolução", com relevância média de 7,45. Em seguida a relevância média de "Funções orgânicas e inorgânicas e reações químicas" foi de 7,34; e a de "Classificação de plantas e animais" foi de 7,25. Os outros três temas do cânone da ciência que apareciam na lista tiveram relevância média abaixo de 7 : "Leis da termodinâmica" ficou com 6,94; "Geocentrismo e Heliocentrismo", ficou com 6,89; e "Cálculos estequiométricos" ficou com 6,40.

Esses dados sinalizam que a demanda por temas que relacionem ciência e tecnologia com questões atuais ligadas à sua vida é grande entre os estudantes secundaristas em geral. Como observam Aikenhead (1994) e Roberts (2007), além dos temas canônicos voltados para a formação de futuros cientistas, é preciso que o ensino de ciências considere que a parcela majoritária dos estudantes não vai seguir carreira científica. Isso não exclui da proposta curricular o cânone da ciência, mas dá força a temas socioambientais que podem ser ponto de partida para o ensino de conhecimentos científicos tradicionais. 
A seguir, apresentaremos a segmentação dos dados da pesquisa por gênero do respondente, por tipo de escola do respondente e, posteriormente, por curso que o respondente pretende fazer na universidade.

\section{Recorte por gênero}

É importante observar que a proporção de meninos e meninas, nesta pesquisa, não reflete o dado estatístico de meninos e meninas matriculados no ensino médio do país. Independentemente do fato de as mulheres poderem ser maioria nas escolas de ensino médio em boa parte dos municípios brasileiros, os dados desta pesquisa de percepção apontam apenas que uma parcela consideravelmente maior de meninas teve interesse em responder ao questionário.

Das meninas que responderam o questionário, 52,8\% estudam em escola pública de ensino regular, 24,9\% estudam em escola pública de ensino técnico e 22,3\% estudam em escola particular. Entre os meninos respondentes, 50\% estudam em escola pública de ensino regular, 28\% estudam em escola pública de ensino técnico e 22\% estudam em escola particular.

O percentual dos que ainda não decidiram qual curso pretende fazer na universidade é ligeiramente maior entre os meninos (43,3\%) do que entre as meninas (40\%). E enquanto, por um lado, a preferência entre as meninas é maior por algum curso de ciências humanas $(24,9 \%)$ ou de ciências biológicas (23,9\%), o maior percentual entre os meninos é o da parcela que escolhe algum curso de ciências exatas (26,6\%).

Há diferenças significativas de opinião entre meninas e meninos quanto ao foco do ensino de biologia, física e química. Enquanto quase metade das meninas $(49,6 \%)$ considera que o foco deveria ser tanto a ciência em si quanto questões sociais relacionadas à ciência, o percentual dos que têm essa opinião cai para 35,6\% entre os meninos. Para 25,8\% dos meninos, o foco do ensino deveria ser a ciência em si, o método científico e suas aplicações; e para 11,5\%, o foco deveria ser maior na ciência em si do que em questões sociais. Somando-se esses dois grupos, eles representam 37,3\% do total de meninos.

Embora também haja diferença percentual considerável na pergunta seguinte, a maioria das meninas $(65,5 \%)$ e dos meninos $(51,7 \%)$ considera que o ensino de biologia, física e química deveria privilegiar tanto a formação de novos cientistas quanto a formação do estudante para tomada de decisões como consumidor e cidadão. Apesar dos dados acima apontarem que uma boa parcela dos meninos considere que o foco do ensino deve ser a ciência, a soma dos meninos que consideram que o ensino deve privilegiar a formação para tomada de decisões $(11,7 \%)$ ou que deve privilegiar mais a formação para tomada de decisões do que a formação de novos cientistas $(14,1 \%)$ representa mais do que um quarto do total.

A maioria das meninas $(51,2 \%)$ e dos meninos $(50,2 \%)$ concorda totalmente que "as intervenções humanas na natureza através da ciência ou da tecnologia não são sempre benéficas e também não são sempre maléficas". A concordância parcial a esta afirmação é de $34 \%$ entre os meninos e 32,9\% entre as meninas.

Tanto entre os meninos quanto entre as meninas, predomina a concordância parcial com a afirmação de que "as soluções da ciência ou da tecnologia para resolver um determinado problema podem, eventualmente, gerar outro tipo de problema": 43,8\% dos meninos e $43,5 \%$ das meninas pensam assim. A concordância total com essa afirmação é de 
$30,6 \%$ entre as meninas e $28 \%$ entre os meninos. Nos dois grupos, é relativamente alta a parcela dos que não concordam nem discordam: 18,4\% das meninas e 18,9\% dos meninos.

A concordância total das meninas sobe para 61,3\% na afirmação de que "para participar de um debate sobre questões envolvendo ciência e tecnologia, é preciso considerar os possíveis riscos e benefícios dos avanços científicos e tecnológicos". Entre os meninos, a concordância total é menor, mas a parcela dos que pensam assim também é maioria: 54,8\%. A concordância parcial a essa afirmação é de $27,5 \%$ entre os meninos e de $23,5 \%$ entre as meninas.

Na lista com doze temas, destacam-se, entre as meninas, as relevâncias médias de "Biodiversidade, desmatamento e preservação ambiental" (9,09); "Efeito estufa, aquecimento global e mudanças climáticas" $(9,03)$; "Vantagens e desvantagens das diversas fontes de geração de energia" (8,23); e "Benefícios e riscos da energia nuclear e acidentes ao longo da história" $(8,22)$. Entre os meninos, a relevância média de "Efeito estufa, aquecimento global e mudanças climáticas" foi de 8,75; a de "Biodiversidade, desmatamento e preservação ambiental" foi de 8,58; a de "Vantagens e desvantagens das diversas fontes de geração de energia" foi de 8,35; e embora a relevância média de "Benefícios e riscos da energia nuclear e acidentes ao longo da história" tenha ficado abaixo de 8 entre os meninos, ficou bem próxima disso: 7,98.

Tanto entre meninas quanto entre meninos, a relevância média dos temas do cânone da ciência ficou abaixo da que eles atribuíram aos temas socioambientais acima. A relevância mais baixa da lista foi para o tema "Cálculos estequiométricos", com média de 6,50 entre os meninos e de 6,35 entre as meninas.

A segmentação de dados apresentada acima, embora mostre diferenças percentuais consideráveis nas respostas de meninos e meninas, sinaliza certas tendências em ambos os grupos, como a concordância apenas parcial de que a solução de um problema pela ciência possa eventualmente gerar outro problema, e a atribuição de alta relevância aos temas socioambientais. A grande diferença de opinião entre meninos e meninas é que praticamente metade delas considera que deve haver um equilíbrio, no foco do ensino de biologia, física e química, entre a ciência em si e as questões sociais ligadas à ciência.

\section{Recorte por tipo de escola}

O percentual de meninos respondentes nas escolas públicas de ensino técnico (40,2\%) é ligeiramente maior que nas escolas particulares $(36,8 \%)$ e nas escolas públicas de ensino regular (36\%). Nestas últimas está o maior percentual dos que ainda não decidiram que tipo de curso fazer na universidade: $47,7 \%$.

Nas escolas particulares, 26,4\% pretendem fazer um curso de ciências biológicas; 20,8\%, um curso de ciências humanas; e 18,8\%, um curso de ciências exatas. Nas de ensino técnico, 23,7\% pretendem fazer um curso de ciências exatas; 19,2\%, um curso de ciências humanas; e 18,6\%, um curso de ciências biológicas. Nas escolas públicas de ensino regular, $22,7 \%$ pretendem fazer um curso de ciências humanas, 16,2\%, um curso de ciências biológicas; e 10,2\%, um curso de ciências exatas.

Se considerarmos apenas os estudantes que já decidiram sua escolha, as ciências humanas são a preferência de 46,3\% nas escolas públicas de ensino regular; as ciências biológicas são a preferência de $40 \%$ nas escolas particulares; e as ciências exatas são a preferência de 38,5\% nas escolas públicas de ensino técnico. 
Na pergunta sobre qual deveria ser o foco do ensino de biologia, física e química, apenas nas escolas públicas de ensino técnico, a maioria dos estudantes (51,9\%) considera que deveria ser tanto a ciência em si quanto questões sociais relacionadas à ciência, embora nas escolas particulares o percentual dos que têm a mesma opinião seja bem próximo disso: 49,2\%. Nas escolas públicas de ensino regular, a parcela dos que defendem esse equilíbrio no ensino cai para 38,7\% e o percentual dos que consideram que o foco do ensino deve ser a ciência em si, o método científico e suas aplicações é o maior (24,6\%) em comparação com o das escolas de ensino técnico (18,9\%) e particulares (16,8\%). O maior percentual dos que consideram que o foco do ensino deveria ser questões sociais relacionadas com ciência e tecnologia está nas escolas particulares (20,8\%); nas públicas de ensino regular, essa é a opinião de 18,4\%; nas de ensino técnico, 15,5\% têm essa mesma opinião.

Na pergunta sobre o que o ensino de biologia, física e química deveria privilegiar, a maioria dos estudantes dos três grupos considera que deveria privilegiar tanto a formação de cientistas quanto a formação para tomada de decisões: essa é a opinião de 66,3\% dos estudantes das escolas públicas de ensino técnico; de 59,2\% dos estudantes de escolas particulares; e de 57,7\% dos estudantes de escolas públicas de ensino regular. Nas escolas particulares, a soma dos que consideram que o ensino deve privilegiar mais a formação para a tomada de decisões do que a formação de cientistas $(16,4 \%)$ e dos que consideram que deve privilegiar a formação para tomada de decisões $(9,6 \%)$ corresponde a mais de um quarto dos estudantes.

A maioria dos estudantes de escolas públicas de ensino técnico (59,5\%) e de escolas particulares $(57,2 \%)$ concorda totalmente que "as intervenções humanas na natureza através da ciência ou da tecnologia não são sempre benéficas e também não são sempre maléficas". Nas escolas públicas de ensino regular, o percentual de concordância total cai para 43,7\%. Concordam parcialmente com essa afirmação 35,8\% dos estudantes de escola pública de ensino regular; 33,2\% dos de escolas particulares; e 28,9\% dos de escolas técnicas.

Nos três segmentos, é maior a parcela dos estudantes que concorda parcialmente que "as soluções da ciência ou da tecnologia para resolver um determinado problema podem, eventualmente, gerar outro tipo de problema": 44,7\% nas escolas públicas de ensino técnico; 44,2\% nas públicas de ensino regular; e 41,2\% nas particulares. A concordância total com essa afirmação é de 34,4\% nas escolas particulares; 30,9\% nas de ensino técnico; e $26,9 \%$ nas públicas de ensino regular. Nesse último segmento, é consideravelmente alto o percentual dos que não concordam nem discordam: 21,3\%.

Embora a maioria, nos três segmentos, concorde totalmente que "para participar de um debate sobre questões envolvendo ciência e tecnologia, é preciso considerar os possíveis riscos e benefícios dos avanços científicos e tecnológicos", o percentual de concordância total é significativamente maior nas escolas particulares $(72,4 \%)$, em comparação com as públicas de ensino técnico $(60,1 \%)$ e de ensino regular $(52,7 \%)$. A concordância parcial com essa afirmação é de 26,8\% nas escolas públicas de ensino técnico, $26 \%$ nas públicas de ensino regular e $20 \%$ nas particulares.

Ao apontarmos acima os dados gerais da pesquisa, quatro temas socioambientais aparecem como os mais relevantes na opinião dos estudantes como um todo. Na segmentação dos dados, dois desses temas se destacam com altíssima relevância, acima de 9, em dois segmentos: "Efeito estufa, aquecimento global e mudanças climáticas" ficou com relevância média de 9,25 entre estudantes de escolas públicas de ensino técnico e 9,23 
entre estudantes de escolas particulares; e "Biodiversidade, desmatamento e preservação ambiental" ficou com 9,19 nas escolas particulares e 9,18 nas de ensino técnico. Nas públicas de ensino regular, as médias são bem próximas para esses dois temas: 8,65 para "Biodiversidade, desmatamento e preservação ambiental" e 8,64 para "Efeito estufa, aquecimento global e mudanças climáticas".

Essa segmentação dos dados por tipo de escola, aprestada nesta seção, sinaliza que o ensino CTS já está relativamente consolidado nas escolas públicas de ensino técnico e nas escolas particulares, pela opinião da maioria de seus estudantes em questões envolvendo as relações entre ciência, tecnologia e sociedade. Uma questão em particular encontra resistência nos três segmentos: para os estudantes, as soluções da ciência ou da tecnologia para resolver um problema não deveriam gerar, nem mesmo eventualmente, outro problema. Trata-se de uma boa questão para se pensar e se discutir em sala de aula. Nas escolas públicas de ensino regular, aparecem os maiores percentuais dos que não concordam nem discordam com determinadas afirmações ou não sabem opinar, o que sinaliza que há mais margem para se trabalhar melhor a abordagem CTS nesse segmento de ensino.

\section{Recorte por tipo de curso escolhido}

As diferenças de gênero se destacam nas escolhas de curso: entre os respondentes que querem fazer algum curso de ciências biológicas na universidade, 77,6\% são meninas e 21,5\% são meninos; dos que querem fazer algum curso de ciências humanas, $72,1 \%$ são meninas e 25,4\% são meninos; entre os que escolhem algum curso de ciências exatas, isso se inverte: $63,4 \%$ são meninos e $36 \%$ são meninas. Entre os que ainda não se decidiram, os percentuais de meninas $(60,6 \%)$ e de meninos $(39,4 \%)$ são bem próximos do universo geral de entrevistados. Já na pequena parcela dos que não pretendem cursar universidade, 55,9\% são meninos e $44,1 \%$ são meninas.

Do total de estudantes que escolhem ciências humanas, 55\% são de escolas públicas de ensino regular, 23,3\% são de escolas públicas de ensino técnico e 21,7\% são de escolas particulares. Entre os que escolhem ciências biológicas, 43,9\% são de escolas públicas de ensino regular, 30,8\% são de particulares e 25,2\% são de ensino técnico. Entre os que escolhem ciências exatas, 39,4\% são de escolas técnicas, 33,7\% de escolas públicas de ensino regular e $23,9 \%$ de escolas particulares. A grande maioria dos estudantes que ainda não se decidiu $(60,3 \%)$ ou não pretende cursar universidade $(55,9 \%)$ é de escolas públicas de ensino regular.

A maioria dos estudantes que escolhem ciências humanas (54,6\%) ou ciências biológicas (52,8\%) considera que o foco do ensino de biologia, física e química deve ser tanto a ciência em si quanto questões sociais relacionadas à ciência. Entre os que não pretendem cursar universidade, essa é a opinião de 41,2\%; entre os que não se decidiram, $38,8 \%$ pensam assim; a parcela dos que defendem esse equilíbrio no ensino cai para 36\% entre os que escolhem ciências exatas. Nesse último segmento, das ciências exatas, está o maior percentual dos que consideram que o foco do ensino dever ser a ciência em si, o método científico e suas aplicações: 29,1\%.

É preciso cautela na interpretação desse dado da opinião dos estudantes que escolhem ciências exatas. Isso não significa que as questões sociais ligadas à ciência não apareçam como foco em propostas de ensino CTS nas áreas de física e química. Vários autores dessas áreas têm contribuições significativas na abordagem CTS. No entanto, boa parte dos 
estudantes considera que o foco do ensino deve ser aquilo que é cobrado nas provas de acesso ao ensino superior, como os vestibulares e o Exame Nacional do Ensino Médio, em que as questões sociais são apenas ilustrativas e secundárias e não estão no foco do conhecimento que está sendo cobrado (ver, por exemplo, ALVES, 2011; CUNHA, 2021).

É bastante alto o percentual dos que consideram que o ensino de biologia, física e química deve privilegiar tanto a formação de cientistas quanto a formação para tomada de decisões, nos grupos que escolhem ciências biológicas (68,7\%), ciências humanas (63,8\%) ou ciências exatas (61,7\%). Embora seja menor a parcela dos que pensam assim entre os que ainda não se decidiram, essa também é a opinião da maioria: 55,8\%. Apenas no pequeno grupo dos que não pretendem cursar universidade, a parcela que defende esse equilíbrio cai para 35,3\%.

Entre os que escolhem ciências humanas, 13,8\% consideram que o ensino deve privilegiar mais a formação para tomada de decisões do que a formação de novos cientistas; e 10\% consideram que o ensino deve privilegiar a formação para tomada de decisões. Entre os que escolhem ciências exatas, os percentuais são bem próximos disso: 13,1\% consideram que o ensino deve privilegiar mais a formação para tomada de decisões do que a formação de novos cientistas e 10,9\% consideram que o ensino deve privilegiar a formação para tomada de decisões.

Um dado que sinaliza uma possível insatisfação de uma parcela dos estudantes com a estrutura curricular de biologia, física e química - ou, pelo menos, acende um sinal de alerta - está entre os que não pretendem cursar universidade. A soma dos que consideram que o ensino deve privilegiar mais a formação para tomada de decisões do que a formação de novos cientistas $(26,5 \%)$ e dos que consideram que o ensino deve privilegiar a formação para tomada de decisões $(17,6 \%)$ chega a $44,1 \%$. Embora representem apenas $3 \%$ do total de respondentes, é preciso considerar a opinião dessa parcela de estudantes nas reflexões sobre o ensino médio.

A maioria dos que escolhem ciências biológicas $(61,7 \%)$ ou ciências exatas $(54,3 \%)$ e metade dos que escolhem ciências humanas (exatos 50\%) concorda totalmente que "as intervenções humanas na natureza através da ciência ou da tecnologia não são sempre benéficas e também não são sempre maléficas". A concordância total com essa afirmação cai para 45,8\% entre os que ainda não se decidiram e para 38,2\% entre os que não pretendem cursar universidade. Esses dois grupos têm os maiores percentuais de concordância parcial: 44,1\% entre os que não pretendem cursar universidade e 36,4\% entre os que ainda não se decidiram.

Em todos os grupos, predomina a concordância parcial com a afirmação de que "as soluções da ciência ou da tecnologia para resolver um determinado problema podem, eventualmente, gerar outro tipo de problema": essa é a opinião de $50 \%$ dos que não pretendem cursar universidade; de 45,1\% dos que escolhem ciências exatas; de 44,4\% dos que escolhem ciências biológicas; de 43,3\% dos que escolhem ciências humanas; e de $42,5 \%$ dos que ainda não se decidiram. A concordância total com essa afirmação fica em 36,4\% entre os que escolhem ciências biológicas; em 32,1\% entre os que escolhem ciências humanas; em $28 \%$ entre os que escolhem ciências exatas; em $26,4 \%$ entre os que ainda não se decidiram; e em 20,6\% entre os que não pretendem cursar universidade.

A maioria dos estudantes, em todos os grupos, concorda totalmente que "para participar de um debate sobre questões envolvendo ciência e tecnologia, é preciso considerar os possíveis riscos e benefícios dos avanços científicos e tecnológicos": essa é a 
opinião de $66,8 \%$ dos que escolhem ciências biológicas; de 64,7\% dos que não pretendem cursar universidade; de 63,3\% dos que escolhem ciências humanas; de 56\% dos que escolhem ciências exatas; e de 53,8\% dos que ainda não se decidiram. Trata-se de um dado relevante, pois tanto no grupo majoritário dos indecisos quanto no grupo minoritário dos que não pretendem cursar universidade - além, é claro, dos grupos que já fizeram suas escolhas -, predomina a opinião de que os benefícios e os riscos da ciência e da tecnologia precisam ser considerados em debates sobre esse tema.

No recorte por tipo de escola, apresentado acima, apontamos que dois temas socioambientais foram considerados de altíssima relevância por estudantes de escolas particulares e de escolas públicas de ensino técnico. Na segmentação por tipo de curso que o estudante pretende fazer na universidade, aqueles mesmos temas aparecem no topo da lista: os que escolhem ciências biológicas atribuem relevância média de 9,43 para "Biodiversidade, desmatamento e preservação ambiental", que ficou com 9,21 entre os que escolhem ciências humanas. Já o tema "Efeito estufa, aquecimento global e mudanças climáticas" tem relevância média acima de 9 em três grupos: 9,38 para os que escolhem ciências biológicas; 9,23 para os que escolhem ciências humanas; e 9,11 para os que escolhem ciências exatas.

O tema "Vantagens e desvantagens das diversas fontes de geração de energia" teve relevância média de 8,65 para estudantes que querem cursar ciências biológicas, 8,64 para os que querem cursar ciências exatas, e 8,35 para os que querem cursar ciências humanas. O tema "Benefícios e riscos da energia nuclear e acidentes ao longo da história" ficou com média de 8,56 para os que escolhem ciências humanas, 8,40 para os que escolhem ciências biológicas, e 8,37 para os que escolhem ciências exatas. Desses quatro temas socioambientais do topo da lista, "Vantagens e desvantagens das diversas fontes de geração de energia" ficou com média abaixo de 8 apenas entre os que ainda não decidiram o tipo de curso que pretendem fazer $(7,93)$; já "Benefícios e riscos da energia nuclear e acidentes ao longo da história" ficou com 7,74 entre os que ainda não se decidiram e com 7,41 entre os que não pretendem cursar universidade.

Um único tema do cânone da ciência ficou com relevância média acima de 8 em um dos grupos: "As Leis de Newton" ficou com 8,19 entre os que pretendem cursar ciências exatas. Para esse grupo, o único tema com média abaixo de 7 foi "Classificação de plantas e animais": 6,66. Entre os que escolhem ciências humanas, dois temas tiveram média abaixo de 7: "Leis da termodinâmica" $(6,78)$ e "Cálculos estequiométricos" (6,11). Este último tema também teve média abaixo de 7 entre os que escolhem ciências biológicas $(6,84)$, os que ainda não se decidiram $(6,14)$ e os que não pretendem cursar universidade $(5,74)$.

É curioso observar que os estudantes que escolhem ciências humanas atribuem relevância maior para "A Teoria da Evolução" $(7,73)$ do que os que escolhem ciências biológicas $(7,63)$; e também atribuem relevância maior a "Geocentrismo e Heliocentrismo" $(7,20)$ do que os que escolhem ciências exatas $(7,13)$. Ambos os temas se relacionam com abordagens de ensino que tratam da história da ciência, e o aspecto histórico pode ter contribuído para a relevância atribuída pelos estudantes que pretendem fazer algum curso de ciências humanas. 


\section{Considerações finais}

Os dados desta pesquisa de percepção sobre ensino de biologia, física e química reforçam o potencial de propostas de ensino CTS como as de Strieder e Kawamura (2008), que partem de temas geradores, com debates sobre questões socioambientais, para abordar conhecimentos científicos tradicionais. Trata-se não apenas de contextualizar o conhecimento científico, mas de atender a uma demanda dos estudantes por um ensino mais significativo e mais ligado à sua realidade, pois, como lembram Aikenhead (1994) e Roberts (2007), apenas uma minoria dos estudantes vai seguir carreira científica. No entanto, todos eles, independentemente de gênero, tipo de escola em que estudam ou tipo de curso que pretendem fazer, atribuem alta relevância aos temas socioambientais apresentados na lista junto a temas do cânone da ciência.

No recorte dos dados por gênero do respondente, vimos que há predominância das meninas entre os estudantes que escolhem ciências biológicas e ciências humanas e que os meninos predominam entre os que escolhem ciências exatas. Muitos estudos tratam da relação entre gênero e escolha profissional, e Lima et al. (2017), por exemplo, em revisão bibliográfica sobre esse tema, mencionam pesquisa sobre a inserção das mulheres em áreas como a química e a física. As opiniões de meninas e meninos com diferença mais significativa são sobre o foco do ensino: para uma boa parcela deles, deveria ser a ciência em si ou maior na ciência do que em questões sociais; e para praticamente metade delas, deveria ser tanto a ciência em si quanto questões sociais relacionadas à ciência.

A segmentação dos dados por tipo de escola em que estudam aponta que nas escolas públicas de ensino regular, que abrangem mais da metade dos respondentes, há uma boa margem para se trabalhar mais as abordagens CTS e tentar engajar um maior número de estudantes em debates sobre questões que impactam suas vidas, pois é relativamente grande a parcela de estudantes, nesse segmento, que não se posicionam em questões opinativas. As respostas dos estudantes de escolas públicas de ensino técnico e de escolas particulares, por outro lado, sinalizam que as relações entre ciência, tecnologia e sociedade são mais trabalhadas e familiares nesses segmentos.

No recorte por tipo de curso que pretendem fazer na universidade, os que escolhem ciências biológicas, ciências humanas e ciências exatas atribuem alta relevância a quatro dos cinco temas socioambientais da lista, o que reforça o potencial desses temas para o público geral de estudantes, independentemente do tipo de curso escolhido. A maioria em todos os grupos, incluindo os que ainda não decidiram o tipo de curso que querem fazer e os que não pretendem fazer universidade, concorda totalmente que para participar de um debate sobre questões envolvendo ciência e tecnologia, é preciso considerar os benefícios e os riscos dos avanços científicos e tecnológicos. Por outro lado, em todos os grupos, predomina a concordância parcial com a afirmação de que a solução de um problema pela ciência pode, eventualmente, gerar outro tipo de problema.

Essa última questão pode ser explorada não apenas em futuro estudo qualitativo com grupo focal de estudantes, mas inclusive em reflexões sobre os sentidos que os estudantes atribuem ao fazer científico. Pode-se inferir, pela respostas dos estudantes, que a solução de um problema que gera outro problema não seria propriamente uma boa solução; deveria ser buscada outra solução que não gerasse o problema secundário ou colateral, até que se chegasse ao nível zero de problema. Se fosse esse o caso, estaríamos diante de uma questão filosófica que daria um ótimo tema para ser debatido com os estudantes: é possível uma ciência "perfeita", que seja sempre capaz de soluções que tenham apenas efeitos 
positivos e não gerem nenhum tipo de problema, que não tenham nenhum impacto negativo, seja social, ambiental ou de que tipo for?

\section{Referências}

AIKENHEAD, G. What is STS Science Teaching? In: SOLOMON, J; AIKENHEAD, G. (Org.). STS education: international perspectives on reform. New York: Teachers College Press, 1994, p. 47-59.

ALVES, A. R. Propostas teórico-metodológicas do Enem: relações entre o enfoque CTS/CTSA e o discurso de professores acerca da prática docente. 2011. 125f. Dissertação (Mestrado em Educação). Departamento de Educação, Universidade Federal de São Carlos, 2011.

CUNHA, R. B. Noção de cidadania é secundária nas questões de ciências da natureza do Enem. Regae: Revista de Gestão e Avaliação Educacional, Santa Maria (RS), v. 10, n. 19, p. 1 22, 2021.

AYALA, F. J. Introductory essay: the case for scientific literacy. In: UNESCO. World science report 1996. Paris: Unesco, 1996. p. 1-5.

BONETT, L. P.; MACHADO, T.; BIANCHI, V. L. T.; FERNANDES, D. O.; ALMEIDA, M. Percepção de alunos do Ensino Médio sobre ciência e tecnologia. EDUCERE - Revista da Educação, Umuarama (PR), v. 8, n. 2, p. 95-117, 2008.

CAMPOS, L. B. de. Proposta de abordagem temática com enfoque CTS no ensino de física: produção de energia elétrica. Dissertação (Mestrado em Educação em Ciências e Matemática). Instituto de Educação. Universidade Federal Rural do Rio de Janeiro, Seropédica (RJ), 2017.

CGEE. Centro de Gestão e Estudos Estratégicos. A ciência e a tecnologia no olhar dos brasileiros - Percepção pública da C\&T no Brasil: 2015. Brasília: CGEE, 2017. 152 p.

CGEE. Centro de Gestão e Estudos Estratégicos. Percepção pública da C\&T no Brasil - 2019. Resumo executivo. Brasília: CGEE, 2019. 24 p.

COELHO, M. A., MORALES, A. P., VOGT, C. Percepção dos professores de ensino médio sobre temas relacionados a ciência e tecnologia. Revista Iberoamericana de Ciencia, Tecnologia y Sociedad - CTS, Buenos Aires, Argentina, v. 11, n. 32, p. 9-36, 2016.

FAPESP. Fundação de Amparo à Pesquisa do Estado de São Paulo. Indicadores de ciência, tecnologia e inovação em São Paulo 2004. São Paulo: FAPESP, 2005.

FAPESP. Fundação de Amparo à Pesquisa do Estado de São Paulo. Indicadores de ciência, tecnologia e inovação em São Paulo 2010. São Paulo: FAPESP, 2011. v. 2.

FERREIRA, S. D. Análise das questões do Enem da área de Ciências Naturais pelo enfoque CTS. 2011. 89f. Dissertação (Mestrado em Educação). Departamento de Educação, Universidade Federal de São Carlos, 2011.

LIMA, F. I. A.; VOIG, A. E. G. T.; FEIJÓ, M. R.; CAMARGO, M. L.; CARDOSO, H. F. A influência da construção de papeis sociais de gênero na escolha profissional. Doxa: Revista Brasileira de Psicologia e Educação, Araraquara (SP), v. 19, n. 1, pp. 33-50, 2017. 
MASCIO, C. C. Exame Nacional do Ensino Médio (Enem): articulações entre a educação ciência, tecnologia e sociedade e a proposta nacional para o ensino de química. 2009. $100 f$. Dissertação (Mestrado em Educação). Departamento de Educação. Universidade Federal de São Carlos. 2009.

MCTI. Ministério de Ciência, Tecnologia e Inovação. Percepção Pública da Ciência e Tecnologia no Brasil. Relatório de pesquisa. Brasília: MCTI, 2010.

MCTI. Ministério de Ciência, Tecnologia e Inovação. Pesquisa de percepção Pública da Ciência. Brasília: MCTI, 2006.

MORALES, A. P, COELHO, M. A. Percepção de alunos e professores da cidade de São Paulo sobre temas relacionados à ciência e à profissão científica. Paakat: Revista de Tecnología y Sociedad, Guadalajara, México, v. 5, n. 8, p. 3-14, 2015.

ROBERTS, D. Scientific literacy/science literacy. In: ABELL, Sandra; LEDERMAN, Nornam (eds.). Handbook of research on science education. New York: Routledge, 2007. p. 729-780.

SANTANA, T. A.; BASTOS, A. P. S.; TEIXEIRA, P. M. M. Nossa alimentação: análise de uma sequência didática estruturada segundo referenciais do Movimento CTS. Revista Brasileira de Pesquisa em Educação em Ciências, Belo Horizonte, v. 15, n. 1, p. 105-122, 2015.

SANTOS, W. L. P. dos. Educação científica na perspectiva de letramento como prática social: funções, princípios e desafios. Revista Brasileira de Educação, Rio de Janeiro, v. 12, n. 36, p. 474-550, 2007

SANTOS, W. L. P. dos; MORTIMER, E. F. Tomada de decisão para ação social responsável no ensino de ciências. Ciência \& Educação, Bauru, v. 7, n. 1, p. 95-111, 2001.

SANTOS, W. L. P. dos; SCHNETZLER, R. P. Educação em química: compromisso com a cidadania. ljuí: Unijuí, 1997.

STRIEDER, R.; KAWAMURA, M. R. Abordagem CTS no contexto escolar: reflexões a partir de uma intervenção. In: Anais do XI Encontro de Pesquisa em Ensino de Física, 2008, Curitiba. Anais do XI Encontro de Pesquisa em Ensino de Física. Curitiba: SBF, 2008.

ZANI, L. B.; PAIVA, C. L.; DUARTE, I. D.; SILVA, M. A. J. A técnica da controvérsia controlada sob a perspectiva do enfoque CTS: uma contribuição para o ensino de biologia. Revista Brasileira de Ensino de C\&T, Curitiba, v. 6, n. 2, p. 62-75, 2013. 